\title{
Tunable Work Function Molybdenum Gate Technology for FDSOI-CMOS
}

Pushkar Ranade ${ }^{1}$, Yang-Kyu Choi, Daewon Ha, Aditya Agarwal ${ }^{\dagger}$, Michael Ameen ${ }^{\dagger}$ and Tsu-Jae King

${ }^{1}$ Materials Science \& Engineering, Electrical Engineering \& Computer Sciences, University of Califormia, Berkeley, CA 94720,

USA, ${ }^{\dagger}$ Axcelis Technologies Inc., 108 Cherry Hill Drive, Beverly, MA 01915, USA

\section{ABSTRACT}

A simple technique for tuning the work function of molybdenum $(\mathrm{Mo})$ gate material over a wide range $(4.5 \mathrm{~V}-$ $4.9 \mathrm{~V})$ is investigated. Ultra-low energy ( $\leq 3 \mathrm{keV}) \mathrm{Ar}^{+}$and $\mathrm{N}^{+}$ion implantation is used to selectively induce structural and/or chemical changes in Mo gate films. These changes are shown to directly affect the Mo gate work function, so that it can be adjusted by adjusting the implant parameters and annealing conditions. The mechanism behind this phenomenon is investigated using $\mathrm{x}$-ray diffraction (XRD) and $\mathrm{x}$-ray photoelectron spectroscopy (XPS). The applicability of this technique for threshold voltage $\left(\mathrm{V}_{\mathrm{TH}}\right)$ control, particularly in fullydepleted SOI CMOS devices, is demonstrated with Mo gated ultra-thin body (UTB) SOI MOSFETs and doublegate FinFETs.

\section{INTRODUCTION}

Advanced transistor structures such as the ultra-thin-body (UTB) MOSFET [1] and the double-gate MOSFET [2] are more scalable than the classical bulk-Si structure and hence are likely to be adopted for the manufacture of CMOS integrated circuits beyond the $50 \mathrm{~nm}$ technology node [3]. Since short-channel effects are effectively suppressed by the use of a thin body, heavy channel doping is not required. The use of a lightly doped channel yields significant performance benefits by way of improved immunity to statistical dopant fluctuation induced variations in threshold voltage $\left(\mathrm{V}_{\mathrm{TH}}\right)$ and enhanced carrier mobility for higher transistor drive current, due to the lower transverse electric field in the inversion layer [4]. However, this requires that the desired $V_{T H}$ be achieved by gate-work-function engineering alone, as the depletioncharge density is too low to affect $\mathrm{V}_{\mathrm{TH}}$. For thin-body CMOS transistors, the required range of gate work functions is 4.4$5.0 \mathrm{~V}$ [5], which precludes doped poly-Si as a gate material. Thus, metallic gate materials will be needed for future fullydepleted SOI technology. In addition, metal gates provide immunity from the gate depletion effect, which will allow a thinner effective dielectric thickness to be maintained.

While two metals with appropriate work functions would ordinarily be required for a symmetric and low $\mathrm{V}_{\mathrm{TH}}$ CMOS technology, a method for tuning the work function of a single deposited metal gate layer over the entire required range would provide for minimal process complexity. It is also desirable to identify metals that are compatible with a conventional "gate-first" process flow. Mo is an attractive candidate because of its excellent compatibility with CMOS processing, low resistivity [6] and a matching coefficient of thermal expanison with the Si lattice. Single crystalline Mo also displays a strong anisotropy in work function (Fig. 1) [7].

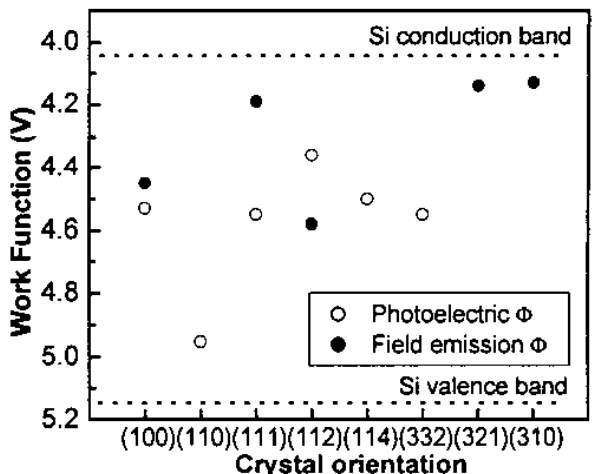

Fig. 1. Variation of Mo work function with crystal orientation (from [7])

In our earlier work, it was shown that $\mathrm{N}^{+}$implantation into Mo films followed by thermal annealing can be used to controllably lower the Mo gate work function [8]. This paper discusses the mechanisms responsible for this effect and also discusses the impact of structural modification on the work function of thin Mo films.

\section{SELECTIVE STRUCTURAL MOdifiCaTION}

In general, densely packed crystallographic surfaces display high work functions since these surfaces are relatively inert with fewer broken atomic bonds. Open crystallographic surfaces display lower work functions owing to a greater number of broken bonds [9]. Amorphous metal films can thus be expected to have lower work functions than their crystalline counterparts.

Mo gate capacitors were fabricated on thermally oxidized p-type Si wafers. In order to account for the influence of oxide fixed charge, multiple $\mathrm{SiO}_{2}$ thicknesses were obtained on a single substrate by selective etchback. Thin Mo films $(15 \mathrm{~nm})$ were sputter deposited to have a predominantly (110) orientation. Subsequent implantation of the metal film with inert ions $\left(\mathrm{Ar}^{+}, 3 \mathrm{keV}, 1 \times 10^{16} / \mathrm{cm}^{2}\right)$ was used to amorphize the microstructure (Fig. 2). The flat-band voltages $\left(\mathrm{V}_{F B}\right)$ of the capacitors were determined from $C-V$ measurements (Fig. 3) and used to extract the gate work functions. Fig. 4 shows the variation of $V_{F B}$ with oxide thickness $\left(T_{O X}\right)$. It can be seen that $\mathrm{Ar}^{+}$implantation lowers the Mo work function by $0.9 \mathrm{~V}$ (to $3.9 \mathrm{~V}$ ), indicating that amorphous Mo has a lower work function. The wafer was then annealed at $500^{\circ} \mathrm{C}$ for $20 \mathrm{~min}$ and the measurements were repeated. The $\mathrm{x}$-ray diffraction (XRD) analysis shown in Fig. 2 indicates that the Mo film is recrystallized after the annealing. As shown in Fig. 4, the Mo 
work function after annealing is high $(4.95 \mathrm{~V})$ and reflects this change in the film morphology.

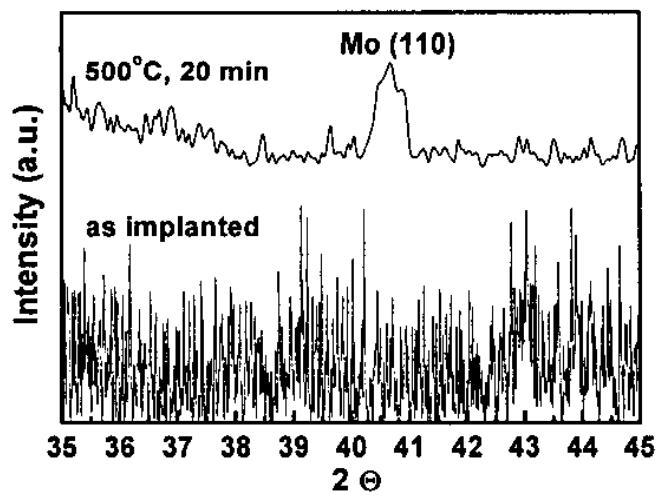

Fig. 2. XRD analysis on Ar implanted Mo films before and after annealing.

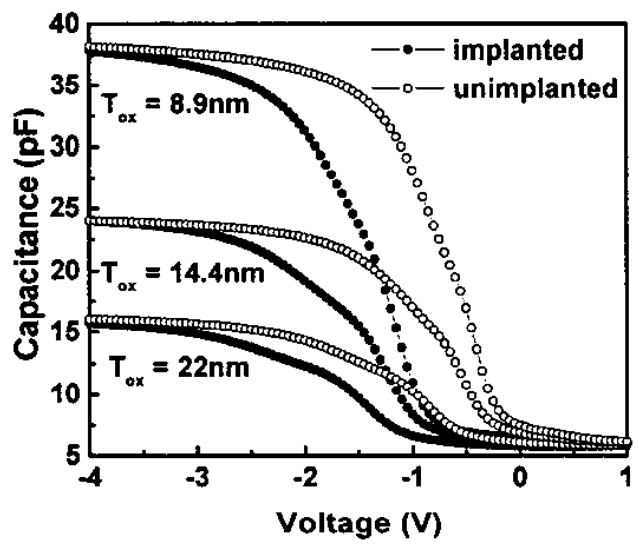

Fig. 3. $\mathrm{C}-\mathrm{V}$ curves for $\mathrm{Mo} / \mathrm{SiO}_{2} / \mathrm{Si}$ capacitors with and without Ar implantation

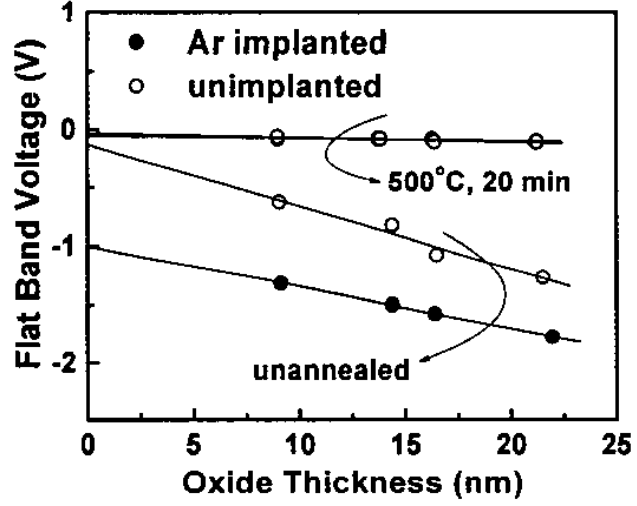

Fig. 4. $V_{F B}$ vs. $T_{O X}$ relationship with and without $\mathrm{Ar}$ implantation. The y-intercept indicates $\Phi_{M S}$

Chemical MOdifiCATION USING $\mathbf{N}^{+}$IMPLANTATION

An alternative approach which modifies the structure and chemistry of the deposited Mo films involves the implantation of $\mathrm{N}^{+}$ions into the metal films instead of inert
$\mathrm{Ar}^{+}$ions. The above experiment was repeated with implantation of $\mathrm{N}^{+}$ions $\left(1 \mathrm{KeV}-5 \times 10^{15} / \mathrm{cm}^{2} ; 2 \mathrm{KeV}-\right.$ $5 \times 10^{15} / \mathrm{cm}^{2}, 1 \times 10^{16} / \mathrm{cm}^{2}$ ) in order to induce a nitridation reaction in the Mo films. Very thin Mo films and ultra-low energy implantation were used in order to minimize ion penetration into the gate dielectric (by lowering the projected range and straggle) while allowing for high atomic $\mathrm{N}$ content (up to $10 \%$ ) within the Mo films. SRIM simulations were used to estimate the $\mathrm{N}$ concentration-depth profiles in the $\mathrm{Mo} / \mathrm{SiO}_{2} / \mathrm{Si}$ stacks (Fig. 5). The evolution of the Mo work function with annealing temperature is shown in Fig. 6. It can be seen that the Mo gate work function $(\sim 4.95 \mathrm{eV})$ decreases with increasing anneal temperature $\left(\mathrm{T}_{\text {anneal }}\right)$, and saturates at $\sim 4.5 \mathrm{eV}$ for $\mathrm{T}_{\text {anneal }}>900^{\circ} \mathrm{C}$.

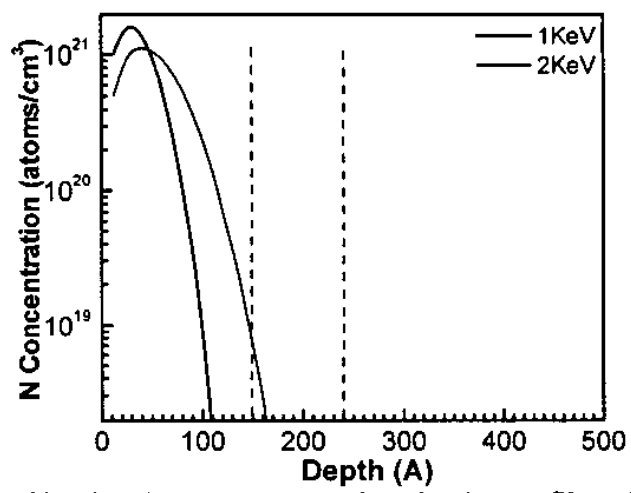

Fig. 5. Simulated $\mathrm{N}$ concentration-depth profiles in the $\mathrm{Mo} / \mathrm{SiO}_{2} / \mathrm{Si}$ stack $\left(\right.$ Dose $\left.=5 \times 10^{15} / \mathrm{cm}^{2}\right)$

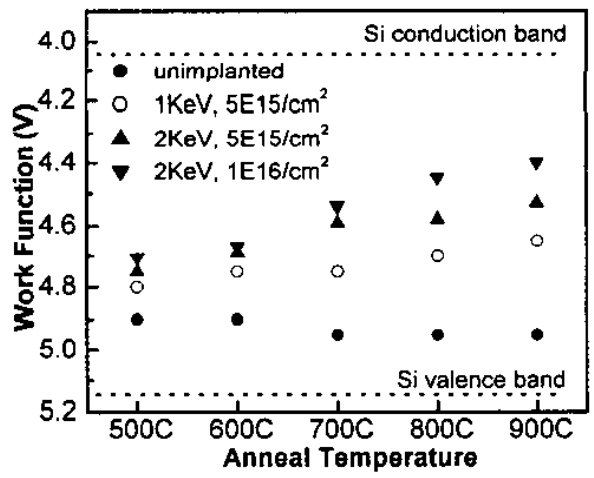

Fig. 6. Variation of Mo work function with thermal annealing. All anneals were $15 \mathrm{~min}$ long except for the $900^{\circ} \mathrm{C}$ anneal (15s).

The cause for this change can be traced to an evolution of the Mo film chemistry with annealing. Fig. 7 shows the results of XRD analysis performed on $\mathrm{N}^{+}$-implanted and unimplanted control samples. The implanted samples show several diffraction peaks corresponding to $\mathrm{Mo}_{2} \mathrm{~N}$. Fig. 8 compares the intensities for the (110) and (112) peaks and indicates the predominantly (110) texture of the Mo film. Fig. 9 shows in more detail the diffraction peaks highlighted in 
Fig. 7. Fig. 10 shows the evolution of the diffraction peaks with implant dose and annealing.

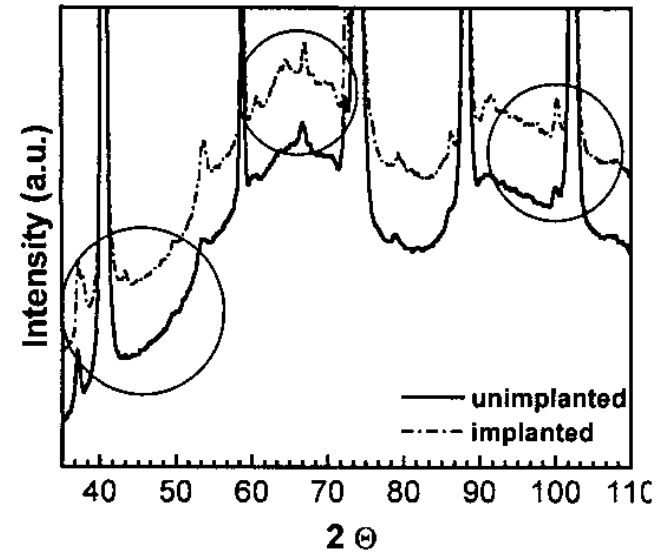

Fig. 7. XRD analysis of $\mathrm{N}$ implanted and unimplanted Mo films. Both samples received a $900^{\circ} \mathrm{C}$ anneal $(15 \mathrm{~s})$. Implant dose $=1 \times 10^{16} / \mathrm{cm}^{2}$

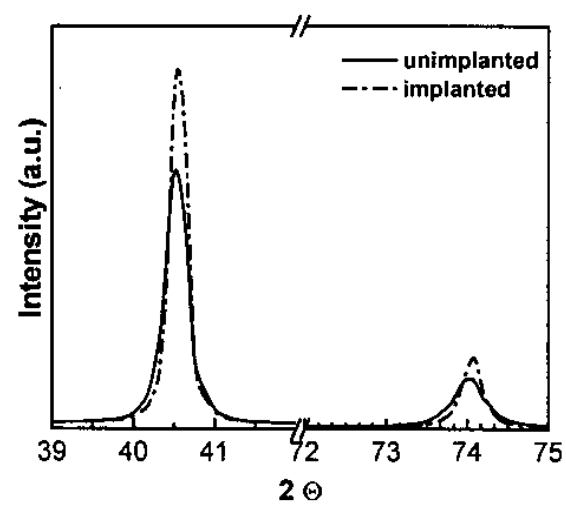

Fig. 8. Comparison of the (110) and (112) peak intensities (the two strongest peaks) indicating the predominantly (110) texture of the film.

It can be seen that increasing the dose or $T_{\text {anneal }}$ leads to an increase in the $\mathrm{Mo}_{2} \mathrm{~N}$ peak intensity. It is hypothesized that increased $\mathrm{T}_{\text {anneal }}$ leads to enhanced segregation of $\mathrm{N}$ at the Mo interface, resulting in a lowering of the interfacial work function. Once the interface is saturated with $\mathrm{N}$, further increase in the annealing temperature does not affect the work function.

To further analyze the chemical changes in the $\mathrm{N}^{+}$ implanted Mo films, XPS analysis was performed. The results of XPS analysis on a sample annealed at $900^{\circ} \mathrm{C}$ are summarized in Fig. 11, which plots the electron count vs. binding energy for Mo and $\mathrm{N}$ signals at several points through the thickness of the Mo film. There is a significant overlap between the Mo $3 p$ peak and the $N$ 1s peak since they are very closely spaced. Therefore, the overall peak was deconvolved to isolate the Mo and the $\mathrm{N}$ contributions. It is seen that a fairly strong $\mathrm{N}$ signal accompanies the Mo signal throughout the thickness of the Mo film. It should also be noted that the XPS analysis does not indicate the formation of $\mathrm{MoO}_{2}, \mathrm{MoO}_{3}$ or $\mathrm{Mo}$ silicide at the $\mathrm{SiO}_{2}$ interface indicating the thermodynamic stability of $\mathrm{Mo}$ and nitrided $\mathrm{Mo}$ on $\mathrm{SiO}_{2}$ at $900^{\circ} \mathrm{C}$.
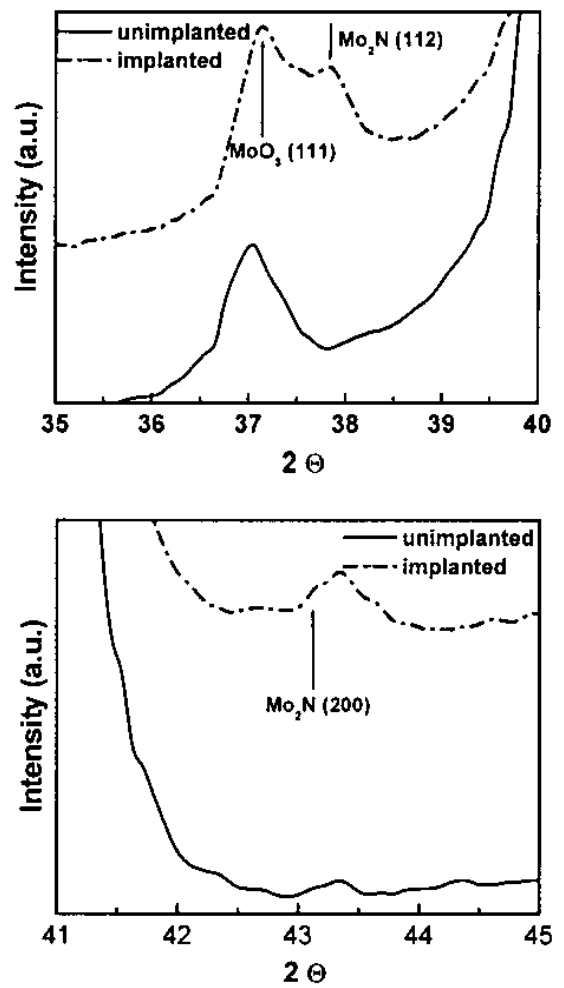

Fig. 9 (a-b). Details of XRD peaks highlighted in Fig. 7.

The solubility and diffusivity of nitrogen in Mo at high temperatures $\left(>1000^{\circ} \mathrm{C}\right)$ have been evaluated earlier [10-11]. While the relevant data for lower temperatures is not readily available, the extrapolated $\mathrm{N}$ diffusion coefficient at $900^{\circ} \mathrm{C}$ is very high $\left(\sim 2 \times 10^{-8} \mathrm{~cm}^{2} / \mathrm{s}\right)$. Low temperature diffusivities in poly-crystalline thin films are expected to be higher than extrapolated values since grain boundary diffusion (lower activation energy) dominates over bulk diffusion. The low solid solubility of $\mathrm{N}$ in $\mathrm{Mo}\left(<1 \%\right.$ at $\left.1000^{\circ} \mathrm{C}\right)$ supports the observed formation of $\mathrm{Mo}_{2} \mathrm{~N}$. The implanted $\mathrm{N}$ atomic content for a dose of $1 \times 10^{16} \mathrm{~cm}^{-2}$ into a $15 \mathrm{~nm}$ Mo film is $\sim 10 \%$ so that the excess $\mathrm{N}$ can readily form $\mathrm{Mo}_{2} \mathrm{~N}$ at elevated temperatures.

\section{MO-GATED THIN-Body MOSFET PERFormanCE}

In order to demonstrate the applicability of the Mo gate technology, p-channel ultra-thin body (UTB) FETs and FinFETs were fabricated with light body doping and Mo as the gate electrode (Figs. 12-13). The p-FET $I_{D}-V_{G}$ characteristics shown in Figs. 12-13 indicate that the unimplanted Mo gate devices have the desired $V_{T H}$. Devices with $\mathrm{N}$ implanted gates show a $\mathrm{V}_{\mathrm{TH}}$ shift in the negative direction, which indicates that the gate work function can be reduced so as to be more suitable for n-FETs. 

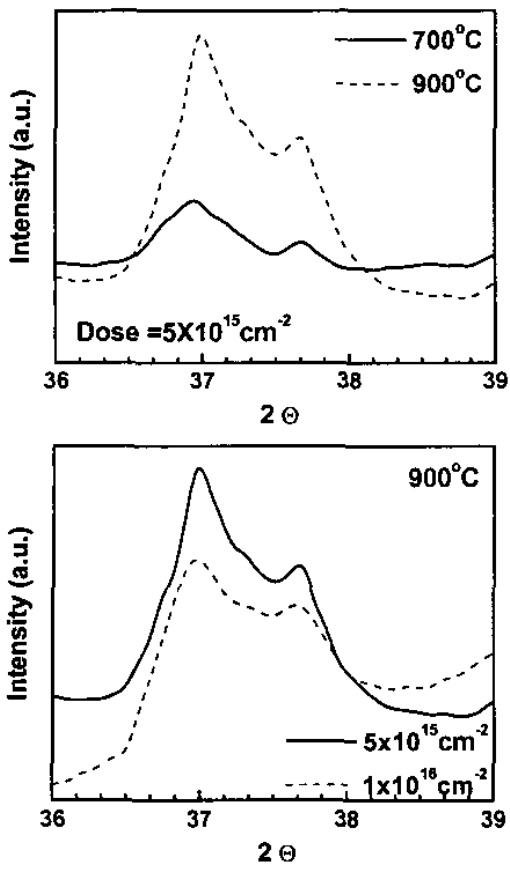

Fig. 10. Dependence of $\mathrm{Mo}_{2} \mathrm{~N}$ (112) $\mathrm{x}$-ray peak intensity on annealing temperature and implant dose.

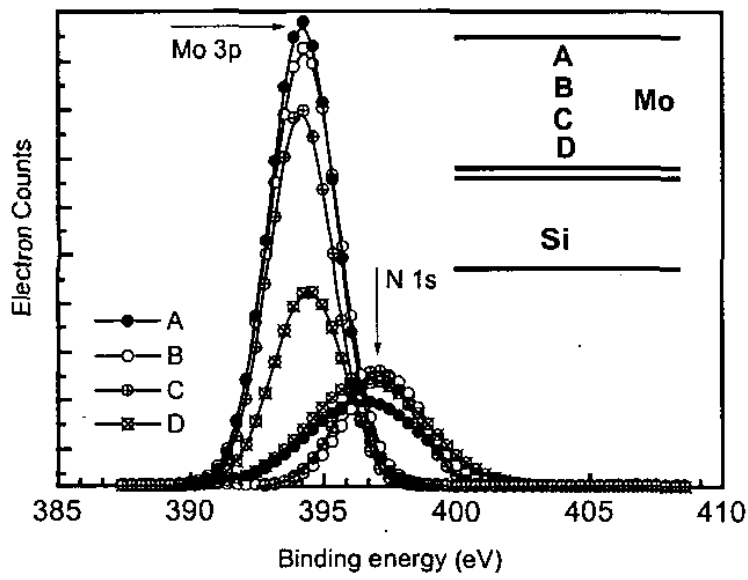

Fig. 11. Mo $3 p$ and $N 1 s$ binding energy at different positions across the Mo film thickness. (Mo film thickness $=150 \AA$, Implant dose $=1 \times 10^{16} / \mathrm{cm}^{2}, 900^{\circ} \mathrm{C}, 15 \mathrm{~s} \mathrm{RTA}$ ).

\section{Conclusion}

Ultra-low-energy $\mathrm{N}^{+}$ion implantation followed by thermal annealing is an effective technique for tuning the gate work function of Mo. The effect is primarily chemical $\left(\mathrm{Mo}_{2} \mathrm{~N}\right.$ formation at the oxide interface) and evolves with increasing annealing temperature up to $900^{\circ} \mathrm{C}$. Mo-gated p-channel UTB FETs and FinFETs show appropriate $\mathrm{V}_{\mathrm{TH}}$, shifting as expected as a function of the ion implant dosage. Mo gate technology is therefore promising for future FDSOI-CMOS application, particularly when multiple values of $\mathrm{V}_{\mathrm{TH}}$ are needed.

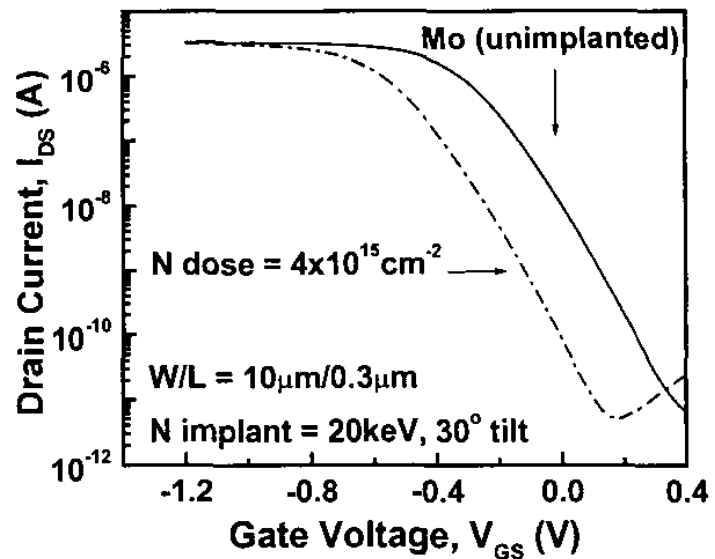

Fig. 12. $I_{D}-V_{G}$ characteristics for a Mo gated PMOS UTBFET with and without $\mathrm{N}$ implantation. Implantation increases the device $\mathrm{V}_{\mathrm{TH}}$ due to a lowering of the gate work function.

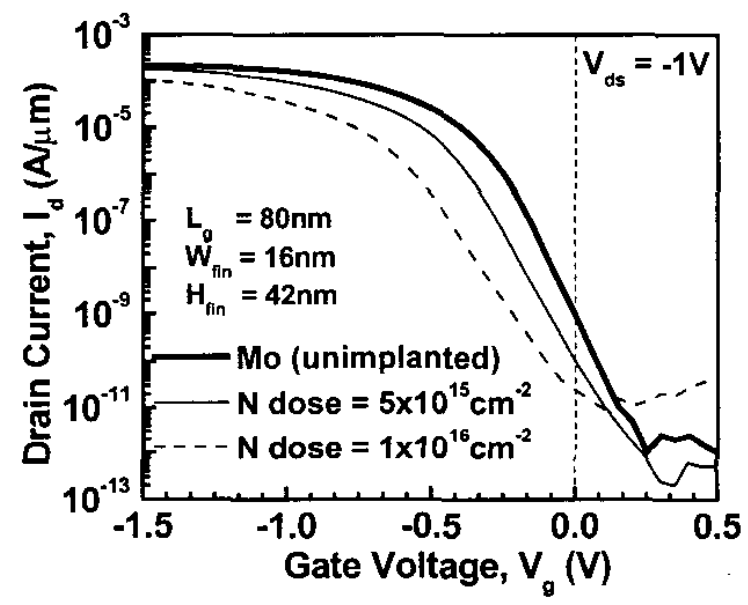

Fig. 13. $I_{D}-V_{G}$ characteristics for a Mo gated PMOS FinFET with and without $\mathrm{N}$ implantation. Implantation controllably shifts the curve to more negative gate biases, indicating a lowering of the gate work function.

Support from SRC-MARCO under contract 2001-MT-887 and the UC Berkeley Microfabrication Laboratory is gratefully acknowledged.

\section{REFERENCES}

1. Y.-K. Choi et al., IEEE Electron Dev. Lett., 21, p. 254, 2000

2. D. Frank et al, IEDM Technical Digest, p. 553, 1992

3. R. Chau et al., IEDM Technical Digest, p. 621, 2001

4. D.A. Antoniadis, 2002 Symp. VLSI Tech., p. 2, 2002

5. L. Chang et al., IEDM Technical Digest, p. 719, 2000

6. VLSI Elec. Microstructure Sci. 9 (Academic Press, 1985), p. 41

7. H. Michaelson, J. Appl. Phys., 48, p. 4729, 1977

8. P. Ranade et al., Electrochem. \& Sol-State Lett., 5, p. G85, 2001

9. R. Smoluchowski, Physical Rev., 60, p. 661, 1941

10. G. Qi et al., Met. Trans. B, v.22, p. 219, 1991

11. J. H. Evans et al., Acta Metallurgica, v. 17, p. 1109,1969 